\title{
Determination of vanadium, molybdenum and tungsten in complex matrix samples by chelation ion chromatography and on-line detection with inductively coupled plasma mass spectrometry
}

\author{
Chiung-Yi Huang, N.-Ming Lee, Shu-Yu Lin, Chuen-Ying Liu* \\ Department of Chemistry, National Taiwan University, 1, Section 4, Roosevelt Road, 10764 Taipei, Taiwan
}

Received 10 December 2001; received in revised form 6 May 2002; accepted 10 June 2002

\begin{abstract}
In this work, two kinds of chelating resin, bis(2-aminoethylthio)methylated resin (BAETM) and $\gamma$-aminobutyrohydroxamate resin $(\gamma$-ABHX) were synthesized. Of these, the former has a hydrophobic skeleton, and the latter a hydrophilic skeleton. The functionalities of each were 0.91 and $2.21 \mathrm{mmol} \mathrm{g}^{-1}$, respectively. The chelating behavior of these resins towards vanadium, molybdenum and tungsten as a function of $\mathrm{pH}$ was studied. To perform trace metals analysis in complex matrices, a hyphenated method-chelation ion chromatography (CIC) coupled on-line detection with inductively coupled plasma mass spectrometry (ICP-MS) was developed. With a BAETM resin column $(5 \times 0.4 \mathrm{~cm}$ i.d.) as the separator, a sample volume of $20 \mu l$, nitric acid $(\mathrm{pH} 1.5)$ as the eluent and a flow rate of $1 \mathrm{ml} \mathrm{min}^{-1}$, the detection limits for the determination of vanadium, molybdenum and tungsten were lower than $0.05 \mathrm{ng} \mathrm{ml}^{-1}$ and the linear ranges were up to $100 \mathrm{ng} \mathrm{ml}^{-1}$ for each element. By increasing the injected sample volume to $250 \mu \mathrm{l}$, the resin concentrator improved the detection limit to $0.01 \mathrm{ng} \mathrm{ml}^{-1}$. For the determination of these elements $\left(5 \mathrm{ng} \mathrm{m}^{-1}\right.$ for each) spiked in artificial sea water samples, $\gamma$-ABHX resin column $(3 \times 0.6 \mathrm{~cm}$ i.d. $)$ demonstrated well resolved peak separation between the analytes and the matrix elements-calcium and magnesium, by using sodium nitrate $\left(10 \mathrm{ml}, 10^{-4} \mathrm{M}\right)$ as the eliminator.
\end{abstract}

(c) 2002 Elsevier Science B.V. All rights reserved.

Keywords: Chelating resin; Chelation ion chromatography; On-line detection; ICP-MS

\section{Introduction}

In the last decade, inductively coupled plasma mass spectrometry (ICP-MS) has emerged as one of the most powerful techniques in inorganic trace analysis. The favorable combination of low detection limits, relatively simple spectra and versatility with respect to sample introduction devices has led to it becoming the method of choice for many trace and ultra-trace

\footnotetext{
* Corresponding author. Tel.: +886-223630231; fax: +886-223638543.

E-mail address: cyliu@ccms.ntu.edu.tw (C.-Y. Liu).
}

elemental analyses. However, a number of difficulties may still be encountered in the analysis of complex matrix samples, such as biological samples or seawater. Many works relating ICP-MS interfaced with ion chromatography have been applied to simultaneous and multi-element analytical techniques for the determination of trace elements [1-7]. The concentrated salt solutions tend to influence the nebulization efficiency due to the high viscosity. In addition, the interferences due to polyatomic ions cause a serious problem [8].

For the determination of trace metals in complex sample matrices with chelating resins, termed as 
chelation ion chromatography (CIC), has received considerable attention in recent years [9-17]. The selectivity of a chelating resin is attributed mainly to the nature of the immobilized ligand on the base matrix. The chelating stationary phase can be formed by chemical bonding, impregnation or dynamic loading, either on polystyrene or silica based substrates. A review of high performance CIC has been published by Jones and Nesterenko [10], as well as Paull and Haddad [13]. Most of the studies so far using CIC have involved the lower valence metal ions, but little work has yet been published involving the separation of high valence metal ions. Sutton et al. [18] used neutral polystyrene resins impregnated with either calmagite or 4-(2-pyridylazo)resorcinol to separate uranium from thorium. In a similar approach, Paull and Haddad [19] impregnated the resin with methylthymol blue to determine trace uranyl ion in saline samples; Cowan et al. [20] dynamically modified the resin with dipicolinic acid for the separation of high valence metal cations. Recently, Truscott et al. [21] also used the neutral polystyrene resin dynamically loaded with dipicolinic acid, but coupled with sector-field ICP-MS for the separation of the actinides.

In the previous work, we found that the introduction of mercaptoethylamine in the polymeric aldehyde could lead to the production of a novel chelating resin [22]. The exceptionally high selectivity for noble metal ions in acidic solution suggests that the prepared resin could be an ideal stationary phase of CIC for selective preconcentration and separation of soft metal ions from complex sample matrix materials. $\gamma$-Aminobutyrohydroxamate resin had been also evaluated as the stationary phase of CIC for the separation of d-orbital elements and f-orbital elements in complex matrices samples $[14,15]$.

Vanadium compounds can be highly toxic to man and animals and their presence in the atmosphere is mainly due to the combustion of fossil fuels, which have important vanadium contents. However, vanadium is an essential trace element, possessing specific physiological functions. For the nutritional and toxicological evaluation of vanadium, it is, therefore, important to establish an accurate and sensitive way for the determination the threshold levels for possible beneficial effects in man, and the point at which harmful effects begin to occur [23]. Molybdenum and tungsten are similar chemically. They exhibit quite differentiated physiological functions, especially in oxygen transfer and nitrogen fixation [24]. In biological systems, molybdenum will be bound through carboxy group or hydroxyl groups of tyrosine and serine residues. However, from studies with -SH binding agents, cysteine is a likely binding site of the metal ion [25]. Based on the above mentioned properties, chelating resins containing both soft and hard ligands were employed as the stationary phases of CIC and on-line detection with ICP-MS for the determination of trace amounts of molybdenum, tungsten and vanadium in complex matrix sample.

\section{Experimental}

\subsection{Apparatus}

The chromatographic system was a Dionex ion chromatography 4000i equipped with a $20 \mu \mathrm{l}$ loop. The separation column was packed with chelation resins prepared as described previously [18,22]. The ICP-MS instrument was a PE SCIEX Elan 6000 (Perkin-Elmer, Norwalk, CT, USA). A cross-flow nebulizer with a Scott type double pass spray chamber was used.

\subsection{Reagents}

All eluents and standards were prepared from analytical reagent grade chemicals (Merck, Darmstadt, Germany) and pure water ( $18 \mathrm{M} \Omega \mathrm{cm}$, Milli-Q water purification system, Millipore, Bedford, MA, USA) under a class 100 laminar flow hood. Ammonium molybdate, sodium tungstate, vanadyl sulfate, nitric acid, potassium bromide, acetic acid, sodium acetate, sodium hydrogen carbonate, sodium carbonate, sodium hydroxide, sodium chloride, potassium chloride, calcium chloride, magnesium chloride, sodium sulfate, oxalic acid, ethylenediaminetetraacetic acid (EDTA), ethylene diamine, sodium nitrate, hexamethylenetetraamine, paraformaldehyde, zinc chloride, and sodium iodide (Merck, Darmstadt, Germany), thiourea, sodium azide, and silver nitrate (Wako, Japan) were purchased from the indicated sources. XAD-4 (polystyrene-divinylbenzene copolymer) and 
2-mercaptoethylamine, as the hydrochloride were purchased from Sigma.

\subsection{Preparation of bis(2-aminoethylthio)methylated resin [22]}

Polystyrene-divinylbenzene copolymer (PS) was immersed in an acidic solution $(\mathrm{HCl}, 6 \mathrm{M})$ for $1 \mathrm{~h}$. After filtration, the resin was washed with water, methanol and acetone sequentially. The purified material was then ground and sieved to a particle size of 230-325 mesh. Zinc chloride $(10 \mathrm{~g})$ in concentrated hydrochloric acid $(37 \%, 150 \mathrm{ml})$ was placed in a round-bottom flask. Paraformaldehyde $(15 \mathrm{~g})$ and the purified polystyrene-divinylbenzene $(15 \mathrm{~g})$ were then added slowly to the reaction flask and heated at $70^{\circ} \mathrm{C}$ for 3 days, till the resin turns from colorless to pale yellow. The product (PS- $\mathrm{CH}_{2} \mathrm{Cl}$ ) was collected by filtration under suction and washed sequentially with water and acetone.

Chloromethylated resin, $\mathrm{PS}-\mathrm{CH}_{2} \mathrm{Cl}(4 \mathrm{~g})$ obtained by the mentioned procedures was placed in a flask, to which sodium iodide $(7 \mathrm{~g})$ in acetone $(75 \mathrm{ml})$ was added dropwise. The resultant mixture was reacted under nitrogen at $60^{\circ} \mathrm{C}$ for $24 \mathrm{~h}$. The brownish red product $\left(\mathrm{PS}-\mathrm{CH}_{2} \mathrm{I}\right)$ was collected by filtration under suction.

PS- $\mathrm{CH}_{2} \mathrm{I}(17 \mathrm{~g})$ was placed in the flask containing hexamethylenetetraamine $(33.6 \mathrm{~g})$ in ethanol $(60 \%$, $\mathrm{w} / \mathrm{v} 130 \mathrm{ml}$ ). The resultant mixture was refluxed for 3 days. After cooling, concentrated hydrochloric acid $(37 \%, 50 \mathrm{ml})$ was added dropwise and the heating was continued further for $5 \mathrm{~h}$. The product was collected by filtration under suction and washed with water and calcium carbonate $(10 \%, \mathrm{w} / \mathrm{v} 100 \mathrm{ml})$ sequentially. The product is called PS-CHO.

2-Mercaptoethylamine hydrochloride $(10.3 \mathrm{~g})$ was dissolved in ethanol $(95 \%, 60 \mathrm{ml})$ and concentrated hydrochloric acid $(30 \mathrm{ml})$. When solution had been achieved, PS-CHO (11.3 g) was added. The mixture was reacted at $50^{\circ} \mathrm{C}$ for 3 days till the color of the resin turned from yellow to yellowish-white. After cooling and filtration, the residue was washed with pure water to remove the unreacted 2-mercaptoethylamine. The extent of the washing was verified with the addition of a mixture of sodium azide and iodine, which tests positive for free $-\mathrm{SH}$. In this work, the rate of decolorization was compared with that in a $10^{-5}$ to
$10^{-6} \mathrm{M}$ 2-mercaptoethylamine. The final product is bis(2-aminoethylthio)methylated resin.

\subsection{Preparation of $\gamma$-aminobutyrohydroxamate resin}

The procedures for the preparation have been described previously [26], where acrylonitrile and divinylbenzene copolymer was used as the matrix skeleton.

\subsection{Artificial water}

Artificial water [27] was comprised of sodium chloride $(0.42664 \mathrm{~mol})$, potassium chloride $(0.01058 \mathrm{~mol})$, calcium chloride $(0.01077 \mathrm{~mol})$, magnesium chloride, $(0.05518 \mathrm{~mol})$ and sodium sulfate $(0.02926 \mathrm{~mol})$ per kilogram water.

\section{Results and discussion}

\subsection{Determination of molybdenum, vanadium and tungsten with ICP-MS}

Molybdenum and tungsten are similar chemically, although there are differences between them in various types compounds that are not easy to explain. Both Mo and $\mathrm{W}$ have a wide variety of stereochemistries in addition to the variety of oxidation states, and their chemistry is among the most complex of the transition elements [28]. Vanadium is similar in certain respects. The main problem in its chemical analysis is that significant hydrolysis and polymerization can occur unless the $\mathrm{pH}$ is quite low [20]. Thus, the post-column determination of these elements with UV-VIS detection, which is the most common way in chromatography, is not easy. Another drawback for the CIC with UV-VIS detection is that the optimum conditions for the post-column reaction conflict with the elution conditions in most cases. Hence in this work, ICP-MS on-line detection followed the CIC separation was investigated.

Nebulizer gas flow rate and radio frequency (RF) power are the most important parameters for the analytical performance of ICP-MS. Fig. 1 shows the dependence of analyte signals on the nebulizer flow rate for a certain range of RF power. The results indicated that a higher intensity could be obtained 

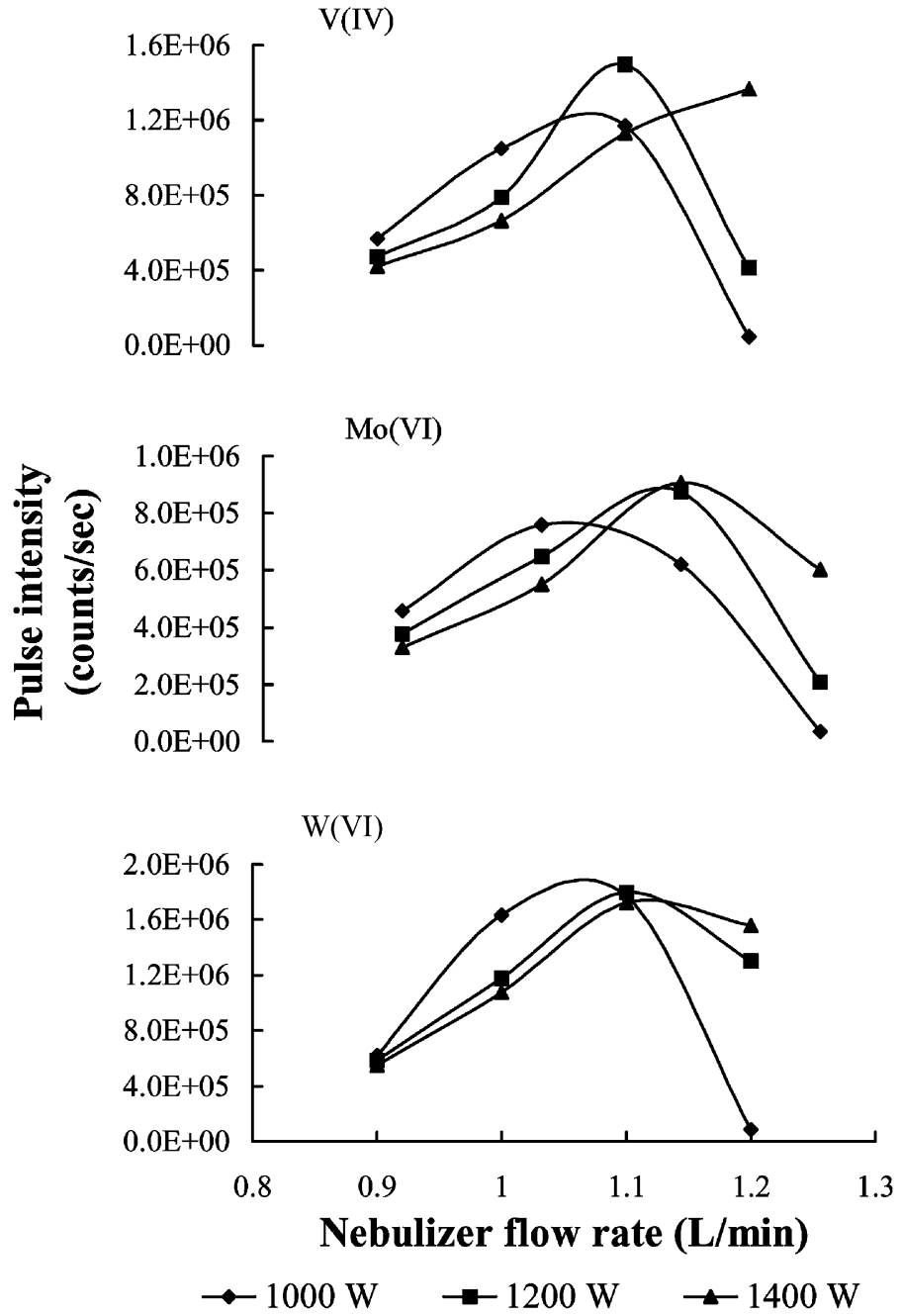

Fig. 1. Dependence of vanadium, molybdenum and tungsten signals on nebulizer gas flow rate for a range of radio frequency (RF) power.

when the condition was kept at $1200 \mathrm{~W}$ and $1.1 \mathrm{ml} \mathrm{min}{ }^{-1}$. The optimized operating conditions for the determination of these elements are listed in Table 1.

\section{2. $p H$ effect on the retention of molybdenum, tungsten and vanadium}

In this work, two different resin columns were tested to find the most suitable conditions for the separation of molybdenum, tungsten and vanadium. Fig. 2 indicates the proposed structures of bis(2-amin- oethylthio)methylated resin (BAETM) and $\gamma$-aminobutyrohydroxamate resin $(\gamma-\mathrm{ABHX})$. The matrix for the former was styrene-divinylbenzene copolymer, while the latter was acrylonitrile-divinylbenzene copolymer. The $\mathrm{pH}$ dependence of the sorption behavior of these resins toward molybdenum, tungsten and vanadium was tested by the batch equilibrium method. Samples were run in excess resin-ligand concentration. After equilibration, the amount of metal ion in the solution or in the resin phase was determined to calculate the distribution coefficient $(D) . D$ was defined as the concentration ratio of metal ion 
Table 1

Instrumental settings for ICP-MS

\begin{tabular}{ll}
\hline Sampling and skimmer cones & Nickel \\
Argon flow rate $\left(\mathrm{min}^{-1}\right)$ & \\
$\quad$ Plasma gas & 15 \\
Auxiliary & 1.2 \\
Nebulization & 1.1 \\
Sample uptake & 0.9 \\
RF power supply (W) & 1200 \\
Lens voltage (V) & 7.5 \\
Data acquisition & \\
Scanning mode & Peak hopping \\
Dwell time (ms) & 100 \\
Reading/sweep & 1 \\
Sweeps/replicate & 1 \\
Replicates & 5 \\
Isotopes monitored & $51 \mathrm{~V},{ }^{98} \mathrm{Mo},{ }^{184} \mathrm{~W}$ \\
\hline
\end{tabular}

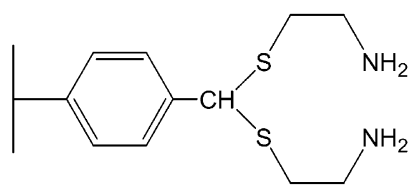

A. bis-(2-aminoethylthio)methylated resin

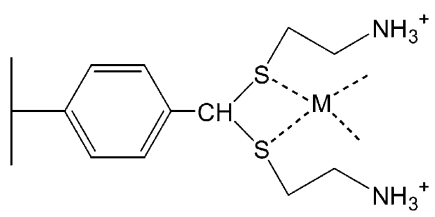

A-1. proposed structure of metal complex at highly acidic medium

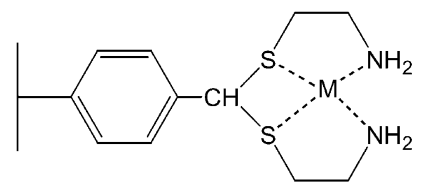

A-2. proposed structure of metal complex at weak acidic or neutral medium

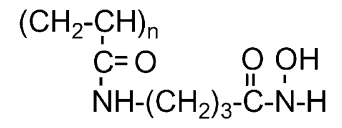

B. $\gamma$-aminobutyrohydroxamate resin

Fig. 2. Proposed structures of the chelating resins; (A) bis(2-aminoethylthio)methylated resin (BAETM); (A-1) metal complex at highly acidic medium; (A-2) metal complex at weak acidic or neutral medium; (B) $\gamma$-aminobutyrohydroxamate resin $(\gamma$-ABHX). in the resin phase $\left(\mathrm{mmol} \mathrm{g}^{-1}\right)$ to the solution phase $\left(\mathrm{mmoll}^{-1}\right)$. To perform this study, acetate buffer $(0.1 \mathrm{M})$ or nitric acid was used for adjusting the $\mathrm{pH}$. The results are shown as Fig. 3. For BAETM, molybdenum, tungsten and vanadium were retained most strongly at $\mathrm{pH}$ around 4 . The affinity increased in the order of vanadium $<$ molybdenum $<$ tungsten (Fig. 3A). As expected, the greater the ionic size, the stronger was the affinity for the soft ligand. Positive molybdenyl ion, $\mathrm{MoO}_{2}{ }^{2+}$ existed in high acidity medium ( $\mathrm{pH} \sim 1$ ), isopoly molybdenum, $\mathrm{Mo}_{x} \mathrm{O}_{y}{ }^{n-}$ existed in $\mathrm{pH}$ around 1 to 2 , while negatively charged molybdate ion, $\mathrm{MoO}_{4}{ }^{2-}$ existed in $\mathrm{pH}$ higher than 4 or 5 [28]. $\mathrm{pH}$ is the dominating parameter in determining adsorption by chelating resin. At highly acidic medium, the amino groups of BAETM are fully protonated. Due to the electrostatic repulsion between the protonated amino group and the positive metal ions, the formation of a four membered chelating ring via the two sulfur donating atoms would be (Fig. 2A-1). The extent of the protonation is decreased by increasing the $\mathrm{pH}$. For the neutral mercaptoethylamine, highly stable metal complex with three chelating rings via the two sulfur and two nitrogen donating atoms would form (Fig. 2A-2). Therefore, the concentration of metal ion on the resin phase can increase as the $\mathrm{pH}$ increase. When the pH was above 4 , highly stable oxyanion, molybdate would form. This resulted in a lower affinity on the resin.

For $\gamma$-ABHX which contains a hard ligand, a different selectivity order compared with that for BAETM at similar condition ( $\mathrm{pH} 4)$ : molybdenum $>$ vanadium $>$ tungsten was observed (Fig. 3B). The order reversal suggests that the soft ligand favors the soft metal ion. By further comparison the adsorption behavior of Mo, $\mathrm{W}$, and $\mathrm{V}$ on these two resins, a rather similar tendency for Mo and $\mathrm{W}$ was indicated at most conditions. Molybdenum blue and tungsten blue could be obtained by mild reduction, for example, by $\mathrm{Sn}$ (II), $\mathrm{SO}_{2}, \mathrm{~N}_{2} \mathrm{H}_{4}, \mathrm{H}_{2} \mathrm{~S}$, etc., of acidic solutions of molybdate and tungstate or of suspensions of $\mathrm{MoO}_{3}$ and $\mathrm{WO}_{3}$ in water. Meanwhile moist tungsten(VI) oxide will acquire a blue tint merely on exposure to ultraviolet light [28]. Since BAETM carries the functional groups of mercaptoethylamine, it would be expected to have a greater reducing power than $\gamma$-ABHX. Therefore, a greater $D$ value was indicated for $\mathrm{W}$ than Mo 

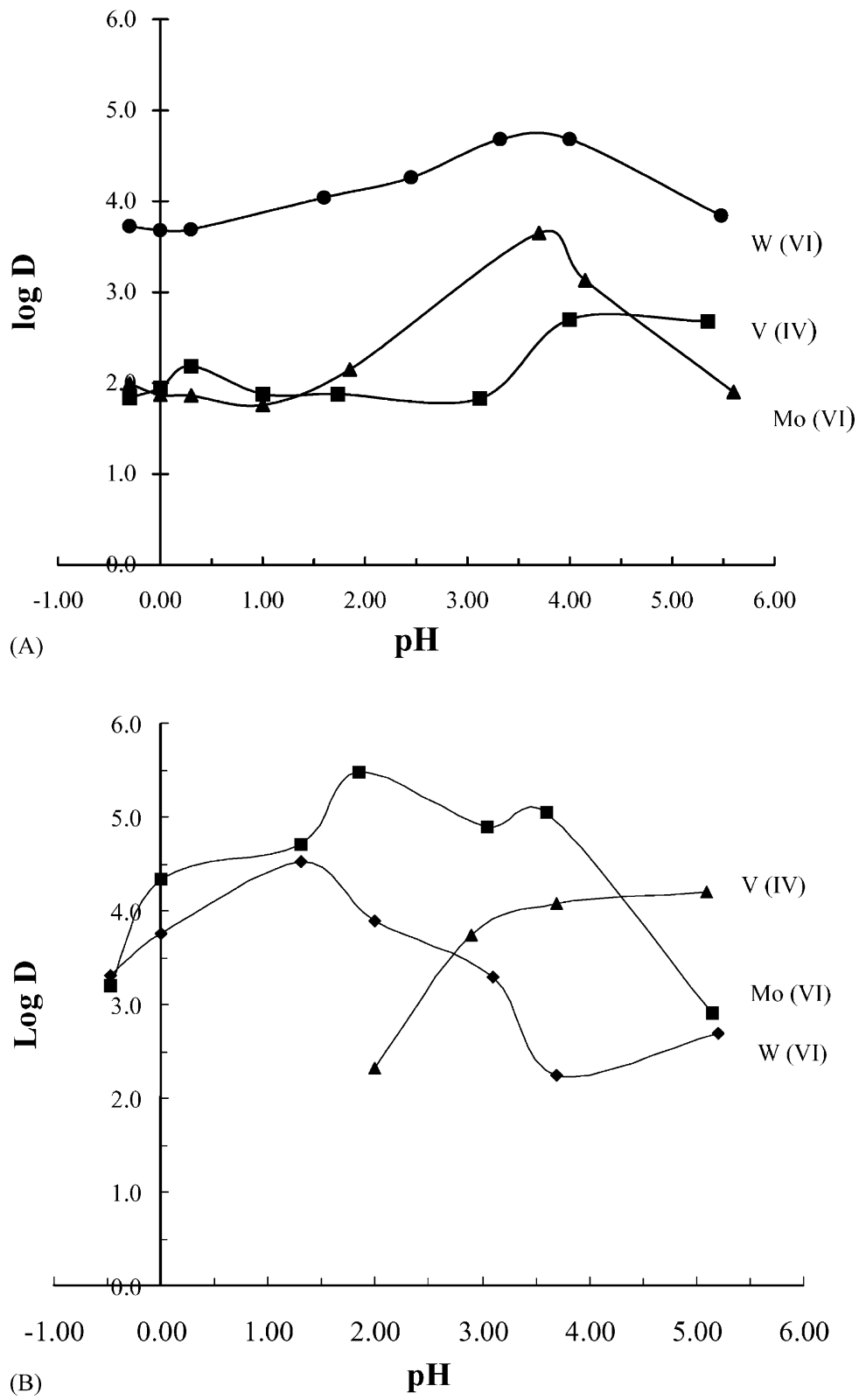

Fig. 3. The sorption of metal ions on the resin as a function of $\mathrm{pH}$. Amount of resin: $0.1 \mathrm{~g}$; volume of solution: $25 \mathrm{ml}$; (A) BAETM resin; (B) $\gamma$-ABHX resin.

on the BAETM resin. Vanadium exhibited a different phenomenon. A favorable retention was observed under the condition of $\mathrm{pH}$ above 4 for both resins. The predominant form of vanadium in acidic media is $\mathrm{VO}^{2+}$ which is the most stable one under ordinary conditions. The functional group, hydroxamic acid on $\gamma$-ABHX is a weak acid (Fig. 2B). Hence, the concentration of metal ion on the resin phase can 
Table 2

Recoveries of metal ions preconcentrated with BAETM resin ${ }^{\mathrm{a}}$

\begin{tabular}{|c|c|c|c|}
\hline Sample & Element & Concentration $\left(\mathrm{ng} \mathrm{ml}^{-1}\right)$ & Recovery (\%) \\
\hline \multirow[t]{3}{*}{ Deionized water } & $\mathrm{V}$ & $9.04 \pm 0.01^{\mathrm{b}}$ & $90.4 \pm 0.1$ \\
\hline & Mo & $11.30 \pm 0.05$ & $113.0 \pm 0.5$ \\
\hline & $\mathrm{W}$ & $2.99 \pm 0.03$ & $29.9 \pm 0.3$ \\
\hline \multirow[t]{3}{*}{ Tap water } & V & $8.58 \pm 0.03$ & $85.8 \pm 0.3$ \\
\hline & Mo & $10.63 \pm 0.08$ & $106.3 \pm 0.8$ \\
\hline & $\mathrm{W}$ & $2.71 \pm 0.02$ & $27.1 \pm 0.2$ \\
\hline \multirow[t]{3}{*}{ Multi-elements in deionized water } & V & $8.43 \pm 0.04$ & $84.3 \pm 0.4$ \\
\hline & Mo & $11.39 \pm 0.06$ & $113.9 \pm 0.6$ \\
\hline & $\mathrm{W}$ & $3.55 \pm 0.02$ & $35.5 \pm 0.2$ \\
\hline \multirow[t]{3}{*}{ Multi-elements in tap water } & V & $7.03 \pm 0.04$ & $70.3 \pm 0.4$ \\
\hline & Mo & $8.21 \pm 0.05$ & $82.1 \pm 0.5$ \\
\hline & W & $3.10 \pm 0.02$ & $31.0 \pm 0.2$ \\
\hline
\end{tabular}

${ }^{\mathrm{a}}$ Metal ion spiked: $1 \mathrm{ng} \mathrm{ml}^{-1}$ for each; BAETM resin: $0.3 \mathrm{~g}$; volume of water sample: $100 \mathrm{ml}$; acetate buffer: $0.1 \mathrm{M}$, $\mathrm{pH} 4$; standing time: $2 \mathrm{~h}$; stripping agent: nitric acid $(10 \mathrm{ml}, 0.1 \mathrm{M})$.

${ }^{\mathrm{b}}$ Five replicates for each data determined by ICP-MS.

increase as the $\mathrm{pH}$ increases due to a decrease in competing $\mathrm{H}^{+}$.

\subsection{Preconcentration}

The commercial chelating resin, Chelex 100 contains a hard ligand, iminodiacetic acid. A low recovery for high valence metal ions preconcentrated by Chelex 100 , but not for other transition metal ions was reported by Itoh et al. [7]. Therefore, BAETM containing the soft ligand was tested as the preconcentrator.

\subsubsection{Recovery of metal ions in various matrix preconcentrated with BAETM resin}

Recovery tests were performed by spiking metal ions $\left(1 \mathrm{ng} \mathrm{ml}^{-1}\right)$ in various matrix samples $(100 \mathrm{ml})$, and then BAETM resin $(0.3 \mathrm{~g})$ was added into it. After stirring for $2 \mathrm{~h}$, the adsorbed metal ions were desorbed with $10 \mathrm{ml}$ nitric acid $(0.1 \mathrm{M})$. It was revealed that a rather low recovery for $\mathrm{W}$ than $\mathrm{V}$ and Mo (Table 2). By comparing with that preconcentrated by Chelex 100 [7], the results were acceptable.

\subsubsection{Effect of the flow rate on the breakthrough capacity}

The breakthrough capacity was dependent on the sample flow rate, sample concentration, metal capacity of the resin and dimension of the resin column. With $1 \mathrm{ng} \mathrm{ml}^{-1}$ of metal ions, the effect of sample flow rate on the breakthrough capacity of BAETM resin column $(5 \times 0.4 \mathrm{~cm}$ i.d.) was studied (Table 3$)$. The breakthrough capacity was increased in the order: $\mathrm{V}<\mathrm{Mo}<\mathrm{W}$ that is consistent with the results of batch study (Fig. 3A). Meanwhile, it was found that at a flow rate faster than $0.8 \mathrm{ml} \mathrm{min}{ }^{-1}$, nearly constant capacity for $\mathrm{V}$ and $\mathrm{Mo}$, but not for $\mathrm{W}$ was indicated.

Table 3

Breakthrough capacity of BAETM resin column ${ }^{\mathrm{a}}$

\begin{tabular}{llc}
\hline Metal ion & $\begin{array}{l}\text { Flow rate } \\
\left(\mathrm{ml} \mathrm{min}^{-1}\right)\end{array}$ & $\begin{array}{l}\text { Breakthrough } \\
\text { capacity }(\mathrm{ng})\end{array}$ \\
\hline $\mathrm{V}(\mathrm{IV})$ & 0.2 & 10.7 \\
& 0.4 & 8.0 \\
& 0.6 & 4.0 \\
& 0.8 & 2.7 \\
& 1.0 & 2.5 \\
$\mathrm{Mo}(\mathrm{VI})$ & 0.2 & 11.3 \\
& 0.4 & 10.7 \\
& 0.6 & 9.0 \\
& 0.8 & 6.7 \\
$\mathrm{~W}(\mathrm{VI})$ & 1.0 & 6.7 \\
& 0.2 & 16.0 \\
& 0.4 & 14.6 \\
& 0.6 & 14.3 \\
& 0.8 & 13.0 \\
& 1.0 & 10.8 \\
\hline
\end{tabular}

Sample solution: $1 \mathrm{ng} \mathrm{ml}^{-1}$ for each.

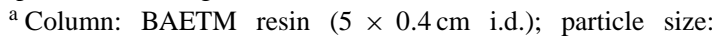
230-325 mesh. 

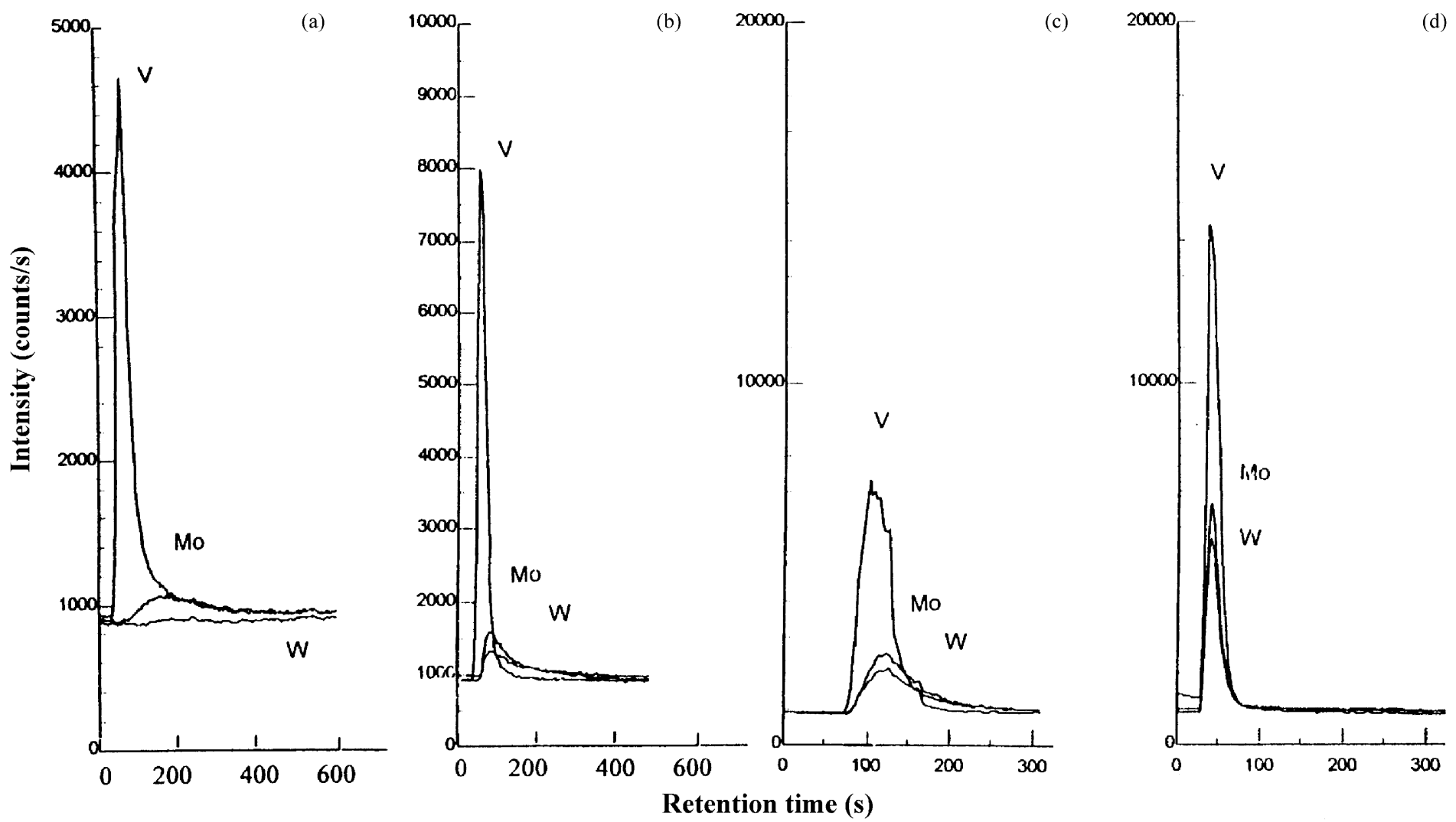

(d)

Fig. 4. Separation of metal ions with BAETM column. Column: BAETM resin $\left(5 \times 0.4 \mathrm{~cm}\right.$ i.d.); sample: mixture of V(IV), Mo(VI) and W(VI), $100 \mathrm{ng} \mathrm{ml}^{-1}$ for each; sample volume: $20 \mu \mathrm{l}$; mobile phase: nitric acid (a) $\mathrm{pH} 3.0$, (b) $\mathrm{pH} 2.5$, (c) $\mathrm{pH} 2.0$, (d) $\mathrm{pH} 1.5$; flow rate: $1 \mathrm{ml} \mathrm{min}^{-1}$. 
Table 4

Retention behavior of metal ion mixture on BAETM resin column ${ }^{\mathrm{a}}$

\begin{tabular}{|c|c|c|c|c|}
\hline \multirow[t]{2}{*}{ Eluents } & \multirow[t]{2}{*}{ Flow rate $\left(\mathrm{ml} \mathrm{min}^{-1}\right)$} & \multicolumn{3}{|c|}{ Retention time (s) } \\
\hline & & $\mathrm{V}$ & Mo & $\mathrm{W}$ \\
\hline Nitric acid (pH 2.5) & 1.0 & 87 & 111 & 111 \\
\hline Nitric acid (pH 3.0) & 1.0 & 90 & 102 & 108 \\
\hline Sodium nitrate $(0.3 \mathrm{mM})$ & 1.0 & 114 & 260 & 284 \\
\hline Sodium nitrate $(0.3 \mathrm{mM})$ & 1.5 & 59 & 84 & 179 \\
\hline Ethylenediamine (0.1 mM, pH 6.5) & 1.0 & 118 & 140 & 124 \\
\hline Ethylenediamine ( $3 \mathrm{mM}, \mathrm{pH} 6.5$ ) & 1.0 & 120 & 117 & 117 \\
\hline Nitrilotriacetic acid (0.1 mM, pH 6.5) & 1.0 & 114 & 117 & 114 \\
\hline EDTA $(0.1 \mathrm{mM}, \mathrm{pH} 4)$ & 1.0 & 90 & 124 & 114 \\
\hline EDTA $(0.1 \mathrm{mM}, \mathrm{pH} 6)$ & 1.0 & 77 & 108 & 105 \\
\hline EDTA (0.1 mM, pH 6.5) & 0.7 & 102 & 151 & 133 \\
\hline
\end{tabular}

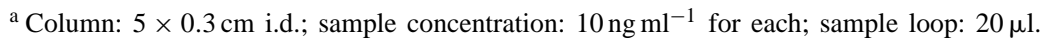

\subsubsection{Choice of stripping agent}

For selecting an appropriate stripping agent, nitric acid is the first acid of choice because it has a background spectrum very similar to that of water. Variation the concentration of nitric acid, the results for the elution were shown as Fig. 4. Although the resolution was getting poor by increasing the acidity of the stripping agent, a sharp peak with greater in- tensity for all metal ions was indicated. An eluent of $\mathrm{pH} 1.5$ (nitric acid) was, therefore, chosen for the further work.

Based on the mentioned results, BAETM column conditioned with acetate buffer $(0.1 \mathrm{M}, \mathrm{pH} 4)$, a sample volume of $20 \mu \mathrm{l}$, nitric acid ( $\mathrm{pH} \mathrm{1.5)}$ as the stripping agent with a flow rate of $1 \mathrm{ml} \mathrm{min}{ }^{-1}$ and ICP-MS pulse detector, calibration curves were constructed for

Table 5

Retention behavior of metal ion mixture on $\gamma$-ABHX resin column ${ }^{\mathrm{a}}$

\begin{tabular}{|c|c|c|c|c|}
\hline \multirow[t]{2}{*}{ Eluents } & \multirow[t]{2}{*}{ Flow rate $\left(\mathrm{ml} \mathrm{min}^{-1}\right)$} & \multicolumn{3}{|c|}{ Retention time (s) } \\
\hline & & $\mathrm{V}$ & Mo & W \\
\hline Nitric acid (pH 3.5) & 1.0 & $>2400^{\mathrm{b}}$ & 81 & 77 \\
\hline Nitric acid (pH 4.0) & 1.0 & $>2400$ & 74 & 74 \\
\hline Sodium nitrate $(0.3 \mathrm{mM})$ & 1.0 & $>2400$ & $>2400$ & 71 \\
\hline Sodium bicarbonate (1 mM) & 1.0 & $>2400$ & 43 & 40 \\
\hline Oxalic acid $(0.1 \mathrm{mM})$ & 1.0 & $>2400$ & 60 & 60 \\
\hline Oxalic acid $(1 \mathrm{mM})$ & 0.8 & 93 & 124 & 108 \\
\hline Oxalic acid $(10 \mathrm{mM})$ & 1.5 & 43 & 50 & 43 \\
\hline Thiourea (0.1 mM, pH 6.5) & 1.0 & $>1000$ & 105 & 105 \\
\hline Ethylenediamine (0.1 mM, pH 6.5) & 1.0 & 118 & $>1200$ & 124 \\
\hline Ethylenediamine ( $3 \mathrm{mM}, \mathrm{pH} 6.0$ ) & 1.0 & 56 & $>1000$ & 53 \\
\hline Ethylenediamine ( $3 \mathrm{mM}$, pH 6.5$)$ & 1.0 & 65 & 170 & 59 \\
\hline Nitrilotriacetic acid (0.1 mM, pH 6.5) & 1.0 & 62 & 62 & 62 \\
\hline EDTA $(0.05 \mathrm{mM}, \mathrm{pH} 6.5)$ & 1.0 & 59 & 59 & 56 \\
\hline EDTA $(0.1 \mathrm{mM}, \mathrm{pH} 7.6)$ & 1.0 & 62 & 105 & 62 \\
\hline EDTA (0.1 mM, pH 6.5) & 0.7 & 56 & 90 & 53 \\
\hline EDTA (0.1 mM, pH 6.0) & 1.0 & 59 & 96 & 59 \\
\hline EDTA $(0.1 \mathrm{mM}, \mathrm{pH} 4.0)$ & 1.0 & 68 & 108 & 65 \\
\hline
\end{tabular}

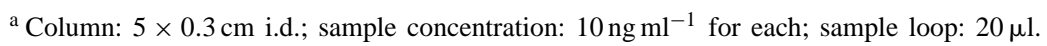

${ }^{\mathrm{b}}$ Peak was not found within the tested time. 

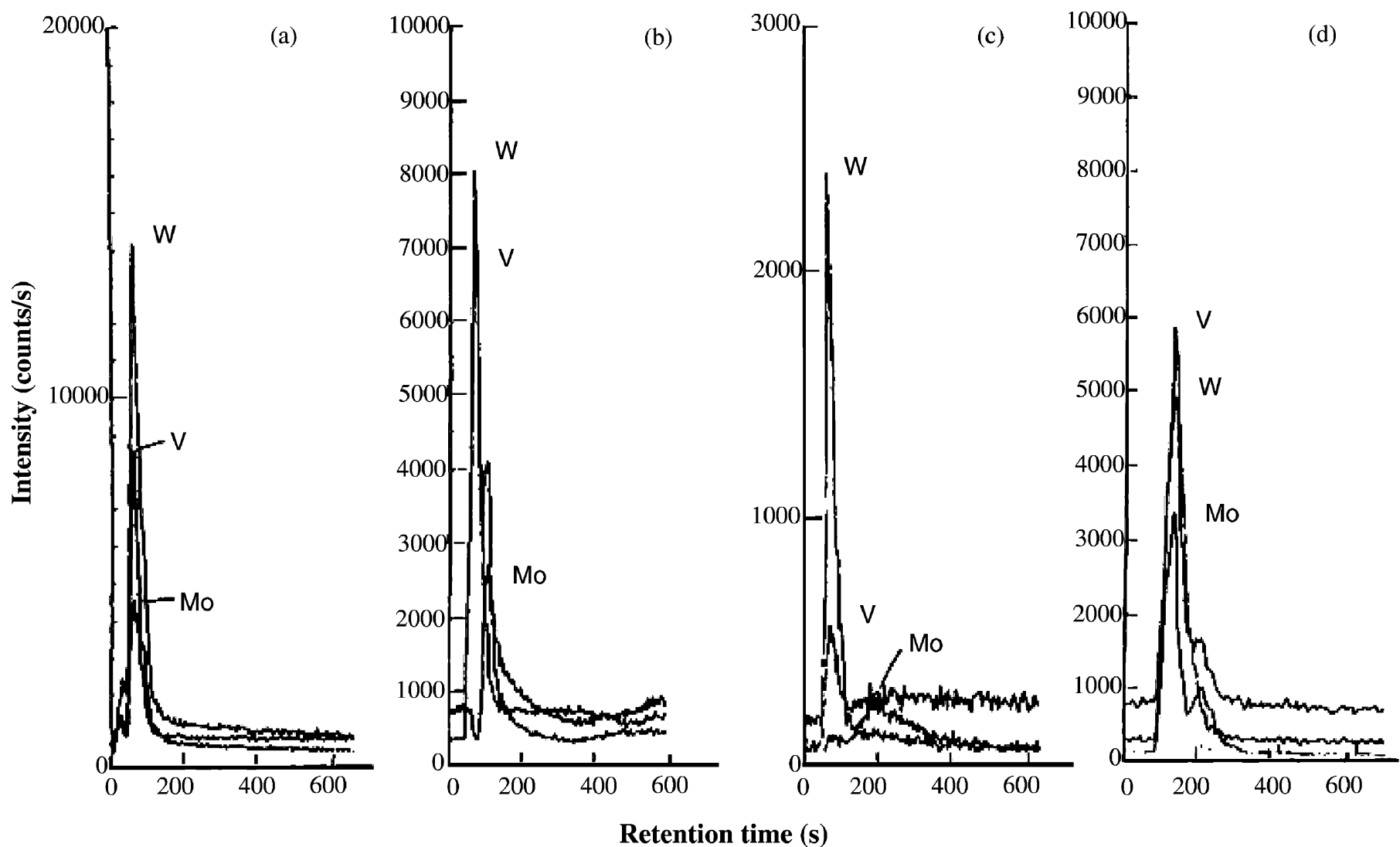

Fig. 5. Separation of metal ions with $\gamma$-ABHX column. Column: $\gamma$-ABHX resin $\left(5 \times 0.4 \mathrm{~cm}\right.$ i.d.); sample: mixture of $\mathrm{V}(\mathrm{IV})$, Mo(VI) and $\mathrm{W}(\mathrm{VI}), 10 \mathrm{ng} \mathrm{ml}^{-1}$ for each; sample volume: $20 \mu \mathrm{l}$; mobile phase: (a) EDTA $\left(5 \times 10^{-4} \mathrm{M}, \mathrm{pH} 6.5\right)$, (b) gradient elution: EDTA $\left(1 \times 10^{-4} \mathrm{M}, \mathrm{pH} 6.5\right) 20 \rightarrow 100 \%(10 \mathrm{~min})$, (c) ethylenediamine $\left(3 \times 10^{-3} \mathrm{M}\right.$, pH 6.5), (d) nitrilotriacetic acid $\left(1 \times 10^{-4} \mathrm{M}, \mathrm{pH} 6.5\right)$; flow rate: $1 \mathrm{ml} \mathrm{min}^{-1}$. 


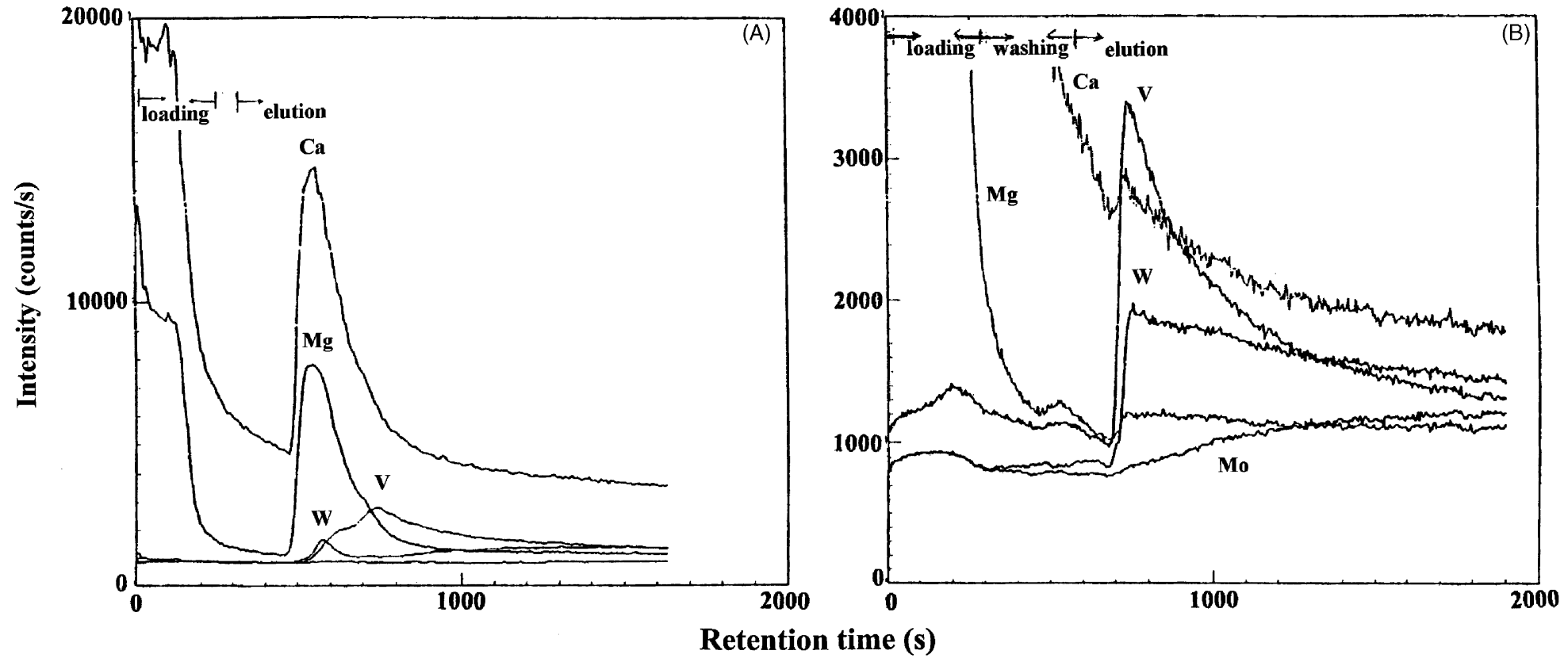

Fig. 6. On-line preconcentration and separation of $\mathrm{V}$, Mo and $\mathrm{W}$ metal ion mixture. Column: $\gamma$-ABHX resin $(3 \times 0.6 \mathrm{~cm}$ i.d.); particle size: $100-140$ mesh; sample: artificial sea water with $10^{4}$-fold dilution and spiked with $5 \mathrm{ng} \mathrm{ml}^{-1}$ metal ion mixture; (A) without elimination; (B) matrix elimination with sodium nitrate (10 ml, $10^{-4} \mathrm{M}$ ). 
all three metal ions. To which $y=883 x+2951$ for $\mathrm{V} ; y=670 x+1907$ for Mo and $y=465 x+812$ for $\mathrm{W}$. The linear ranges were up to $100 \mathrm{ng} \mathrm{ml}^{-1}$ and the detection limits, defined as the three times signal to noise ratio were not larger than $0.05 \mathrm{ng} \mathrm{ml}^{-1}$. In all cases, linearity was greater than 0.9986 within the concentration range examined. By increasing the injected sample volume to $250 \mu$ l, the resin concentrator improved the detection limit to $0.01 \mathrm{ng} \mathrm{ml}^{-1}$.

\subsection{Optimization of elution condition of analyte elements}

According to the adsorption behavior in Fig. 3, only mineral acid seems not a promising eluent in the metal ion separation. In an attempt to find out an appropriate mobile phase, the effects of ionic strength, flow rate of the mobile phase and the addition of other chelating agents, such as ethylenediamine, nitrilotriacetic acid, oxalic acid, thiourea, and EDTA were investigated. The results indicated that the selectivity for these elements on the BAETM resin column was best with sodium nitrate as the eluent (Table 4). No significant difference in retention time was observed with other chelating agents as mobile phase. Aside from $\mathrm{pH}$, ionic strength seems another important factor influencing the chelating properties with the BAETM resin.

For $\gamma$-ABHX resin column, oxalic acid $(1 \mathrm{mM})$ and ethylenediamine ( $3 \mathrm{mM}, \mathrm{pH} 6.5)$ exhibited better resolution among the reagent tested (Table 5). However, EDTA (0.05 mM, pH 6.5) at flow rate of $1.0 \mathrm{ml} \mathrm{min}^{-1}$ gave sharp peaks with greater intensity than any other elution conditions (Fig. 5).

\subsection{Analytical application}

The signal ratio for the determination of $\mathrm{V}$, Mo and $\mathrm{W}\left(5 \mathrm{ng} \mathrm{ml}^{-1}\right.$ for each) spiked into seawater $\left(10^{4}\right.$-fold dilution) by ICP-MS direct determination was $0.75: 0.42: 1$, while that for the pure water was $0.94: 0.41: 1$. The matrix effect for the determination of $\mathrm{V}$ in seawater was obvious.

Thus, the chromatographic behavior of Mo, $\mathrm{V}$ and $\mathrm{W}$ in seawater on $\gamma$-ABHX resin column was investigated. With the resin packed into a PEEK column $(3 \times 0.6 \mathrm{~cm}$ i.d. $)$ and conditioned with sodium acetate buffer $(0.1 \mathrm{M}, \mathrm{pH} 3)\left(4 \mathrm{ml} \mathrm{min}^{-1}\right.$ for $\left.3 \mathrm{~min}\right)$, the mixture of $\mathrm{V}$, Mo and $\mathrm{W}$ ( $5 \mathrm{ng} \mathrm{ml}^{-1}$ spiked for each) in seawater was injected into the system. During sample loading, $\gamma$-ABHX resin column retains not only trace

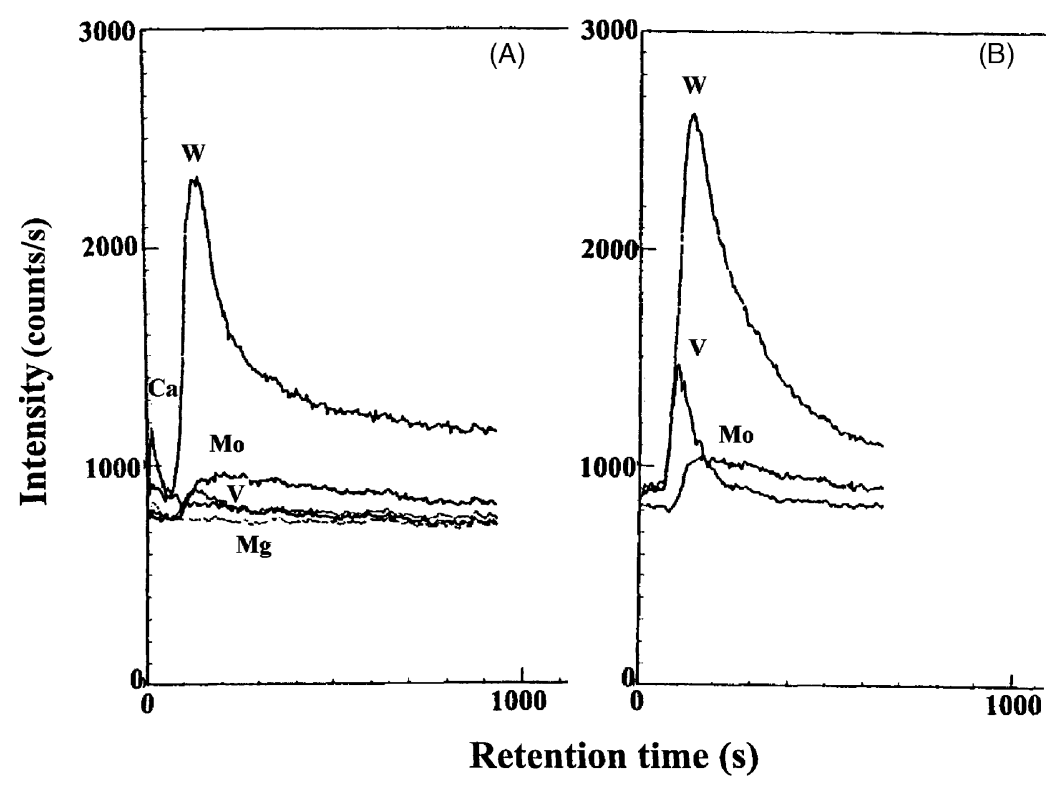

Fig. 7. On-line preconcentration and separation of $\mathrm{V}$, Mo and $\mathrm{W}$ metal ion mixture. Column: $\gamma$-ABHX resin $(1 \times 0.6 \mathrm{~cm}$ i.d.); particle size: 100-140 mesh; sample: metal ions spiked, $5 \mathrm{ng} \mathrm{ml}^{-1}$ for each; (A) artificial sea water; (B) pure water. 
metals but also alkaline-earth metals (Fig. 6A). Therefore, a specific elution of alkaline, and alkaline-earth metals was conducted with sodium nitrate $(0.1 \mathrm{mM}$; $2 \mathrm{ml} \mathrm{min}^{-1}$ for $5 \mathrm{~min}$ ). The analytes could be well resolved from the matrix elements, but strong tailing, as well as a low signal of Mo was indicated (Fig. 6B). A greater intensity of the Mo signal could be observed by increasing the EDTA concentration. Unfortunately, a high concentration of organic reagent is not advantageous for the ICP-MS determination. Here a shorter column $(1 \times 0.6 \mathrm{~cm}$ i.d. $)$ was used instead to reduce the large amount of matrix elements trapped in the column,. In these conditions, not only was there no need for the elimination, but also a greater intensity for Mo and a sharper peak for tungsten were indicated (Fig. 7A). However, by comparison with that for the analysis of pure water (Fig. 7B), an obvious matrix effect for the determination of vanadium was still demonstrated.

\section{Conclusions}

In this work, the CIC technique with bis(2-aminoethylthio)methylated resin and $\gamma$-aminobutyrohydroxamate resin coupling on-line detection with ICP-MS for the determination of vanadium, molybdenum and tungsten was investigated. BAETM was well suited for the preconcentration and determination of these elements at the sub-ppb level, while better results for the determination of these elements in complex matrix samples were obtained by using $\gamma$-ABHX as separator. With sodium nitrate, a simple salt as the eliminator, these elements could be resolved from the matrix elements, calcium and magnesium. Although a greater percentage of vanadium would be lost during the elimination process, it is worthy of further investigation for the determination of molybdenum and tungsten in biological or other complex matrix samples with the $\gamma$-ABHX resin column. Here, we must mention that there are two possible oxidation states of vanadium which can be present in some oxic water samples. Therefore, the speciation study of vanadium, $\mathrm{V}(\mathrm{IV})$ and $\mathrm{V}(\mathrm{V})$ in environmental and biological samples is of special interest. However, $\mathrm{V}(\mathrm{V})$ is readily reduced to $\mathrm{V}(\mathrm{IV})$ by mild reducing agents. Since BAETM resin carries the functional groups of mercaptoethylamine, $\mathrm{V}(\mathrm{IV})$ and $\mathrm{V}(\mathrm{V})$ would be coexist if the reagent of $\mathrm{V}(\mathrm{V})$ was used. Thus, only vanadyl sulfate, namely $\mathrm{V}(\mathrm{IV})$ was investigated.

In this work, seawater was chosen as the model of the complex matrix material since it is a high ionic concentration sample. Therefore, a method established for the trace metal analysis in seawater would be expected an appropriate way for the analysis of those in biological samples.

\section{Acknowledgements}

The authors thank the National Science Council of Taiwan for financial support.

\section{References}

[1] D.T. Heitkemper, N.P. Vela, K.R. Stewart, C.S. Westphal, J. Anal. Atomic Spectrom. 16 (2001) 299.

[2] A. Chatterjee, Y. Shibata, J. Yoshinaga, M. Morita, Appl. Organometal. Chem. 15 (2001) 306.

[3] F. Li, W. Goessler, K.J. Irgolic, J. Chromatogr. A 830 (1999) 337.

[4] C.C. Wann, S.J. Jiang, Anal. Chim. Acta 357 (1997) 211.

[5] J.M. Barrero Moreno, M. Betti, J.I. Garcia Alonso, J. Anal. Atomic Spectrom. 12 (1997) 355.

[6] E.T. Luong, R.S. Houk, R.E. Serfass, J. Anal. Atomic Spectrom. 12 (1997) 703.

[7] A. Itoh, C. Kimata, H. Miwa, H. Sawatari, H. Haraguchi, Bull. Chem. Soc. Jpn. 69 (1996) 3469.

[8] Y. Inoue, H. Kumagai, Y. Shimomura, Anal. Chem. 68 (1996) 1517.

[9] A. Siriraks, H.M. Kingston, J.M. Riviello, Anal. Chem. 68 (1990) 1185.

[10] P. Jones, P.N. Nesterenko, J. Chromatogr. A 789 (1997) 413.

[11] W. Bashir, B. Paull, J. Chromatogr. A 907 (2001) 191.

[12] B. Paull, P. Nesterenko, P.R. Haddad, Anal. Chim. Acta 375 (1998) 117.

[13] B. Paull, P.R. Haddad, Trends Anal. Chem. 18 (1999) 107.

[14] C.Y. Liu, N.M. Lee, T.H. Wang, Anal. Chim. Acta 337 (1997) 173.

[15] C.Y. Liu, N.M. Lee, J.L. Chen, Anal. Chim. Acta 369 (1998) 225.

[16] P.N. Nesterenko, P. Jones, J. Chromatogr. A 770 (1997) 129.

[17] P.N. Nesterenko, P. Jones, J. Chromatogr. A 804 (1998) 223.

[18] R.M.C. Sutton, S.J. Hill, P. Jones, A. Sanz-Medel, J.I. Garcia-Alonso, J. Chromatogr. A 816 (1998) 286.

[19] B. Paull, P.R. Haddad, Anal. Commun. 35 (1998) 13.

[20] J. Cowan, M.J. Shaw, E.P. Achterberg, P. Jones, P.N. Nesterenko, Analyst 125 (2000) 2157.

[21] J.B. Truscott, P. Jones, B.E. Fairman, E.H. Evans, J. Chromatogr. A 928 (2001) 91.

[22] M.J. Chen, C.Y. Liu, J. Chin. Chem. Soc. 46 (1999) 833. 
[23] R. Wuilloud, E. marchevsky, R. Olsina, L. Martinez, J. Anal. Chem. 56 (2001) 77.

[24] W. Kaim, B. Schwederski, Bioinorganic Chemistry: Inorganic Elements in the Chemistry of Life, Wiley, New York, 1994 (Chapter 11).

[25] M.N. Hughes, The Inorganic Chemistry of Biological Processes, 2nd Edition, Wiley, New York, 1985, pp. 173-177.
[26] C.Y. Liu, M.J. Chen, N.M. Lee, H.C. Hwang, S.T. Jou, J.C. Hsu, Polyhedron 11 (1992) 551.

[27] S. Fiol, I. Brandariz, M.S. de Vicente, Mar. Chem. 49 (1995) 215.

[28] F.A. Cotton, G. Wilkinson, Advanced Inorganic Chemistry, 6th Edition, Wiley, New York, 1999. 